\title{
Validation of FGSI Scores in Predicting Fournier Gangrene in Tertiary Hospital
}

\author{
Bambang Sasongko Noegroho \\ Safendra Siregar \\ Akhmad Mustafa (ID) \\ Muhammad Aldito Rivaldi \\ Urology Department, Hasan Sadikin \\ Academic Medical Center, Universitas \\ Padjajaran Bandung, Barat, Indonesia
}

Correspondence: Bambang Sasongko Noegroho

Urology Department, Hasan Sadikin Academic Medical Center, Universitas Padjajaran Bandung, Jl. Pasteur No. 38 Bandung Jawa, Barat, 40I6I, Indonesia

Tel +022 2034953/55

Fax +022 2032216

Email bsn.urologi@gmail.com
Background and Aim: Fournier gangrene (FG) is a necrotizing fasciitis of perineal and/or genital regions that may progressively spread; necrotic tissue may cause morbidity and mortality related to sepsis and multi-organ dysfunction. Surgical intervention required for patients with Fournier gangrene may vary according to the severity of the infection. A Fournier Gangrene Severity Index (FGSI) has been devised to assess the risk of mortality in patients with Fournier gangrene. The aim of this study was to validate the implementation of the FGSI in predicting mortality of FG patients in our hospital.

Methods: A retrospective study was performed on all patients with Fournier gangrene admitted and treated in Hasan Sadikin General Hospital during 2015-2019. Data were collected from the medical records of the emergency room and outpatient clinics. Sociodemographic variables, preexisting comorbidities, outcome, management, and FGSI score were included as variables.

Results: In this study, 83 patients were included from the period 2015-2019, divided into two groups. From the Charlson Comorbidity Index, we found the first group average score was $2.5(0-9)$, and the second group this was 2 (1-8). From the FGSI, in the first group, we found the average score was $5.5(2-15)$, and the average was $14(10-19)$ in the second group, which is significantly higher than the first group $(\mathrm{p}=0.001)$.

Conclusion: We find that the FGSI score system is a good tool for predicting severity of the disease and mortality risk of the patients, which is consistent with findings in other studies. Keywords: FGSI scores, Fournier gangrene, prognosis

\section{Introduction}

Fournier gangrene is a necrotizing fasciitis of perineal, genital, and/or genital regions that may progressively spread; necrotic tissue may cause morbidity and mortality related to sepsis and multi-organ dysfunction. Fournier gangrene initially appears as a cellulitis on the infected region; progressive spread of infection into fascia of the urogenital system may eventually lead to sepsis. ${ }^{1,2}$ Mortality may occur at varying rates, from $4-88 \%$ of all males with the condition. It occurs at a higher frequency in males compared with females. The predisposing factor of Fournier gangrene is related to immunodeficiency. ${ }^{3}$ Incidence in males aged 30-60 years old is approximately $1.6 / 100,000$ persons per year in the USA. ${ }^{4}$ A retrospective study in Spain, of collected data from 2001-2010, showed 37 patients with Fournier gangrene. ${ }^{5}$ In Pakistan, the surgical department in Peshawar revealed 60 patients for the period of 2002-2007. ${ }^{6}$ Fournier syndrome may progress to Fournier gangrene; the risk of progression is particularly higher in individuals with preexisting medical conditions, such as history of steroid use, 
alcoholism, hypertension, smoking, previous trauma, paraphimosis, and other urological conditions. Early surgical intervention and aggressive antibiotic administration are the mainstay of the treatment. Surgical intervention required for patients with Fournier gangrene may vary according to the severity of the infection.

Fournier gangrene is a medical condition with relatively high mortality despite the aggressive and early treatment administered to the patient. As such, a scoring system has been developed in order to aid with the prognostication of the patient. The Fournier Gangrene Severity Index (FGSI) has been devised by Laor et al. in order to assess the risk of mortality in patients with Fournier gangrene. Higher scores were associated with higher risk of mortality; mortality rates had exceeded $75 \%$ with patients scoring more than 9 points in FGSI of 30 patients studied by Laor et al. ${ }^{4}$ The tool is sufficiently sensitive and specific with sensitivity and specificity of $65-88 \%$ and $70-100 \%$, respectively. ${ }^{4,7}$ Yilmazlar et al. suggested the Uludag FGSI (UFGSI) for prognostic score of Fournier gangrene with augmentation to the FGSI scoring system that includes age and extent of disease scores. ${ }^{8}$ The positive A study denoted 8 died of 12 cases with a score $>9$ of UFGSI. ${ }^{9}$ In Hasan Sadikin Hospital, the study concerning of FGSI score and its cut-off point was not yet established. The objective of this study was to validate the factors related to increased mortality and/or morbidity using FGSI scoring in patients with Fournier gangrene treated in Hasan Sadikin General Hospital.

\section{Materials and Methods}

The study was a retrospective study; the patients included in the study were patients with diagnosed Fournier gangrene and treated in Hasan Sadikin General Hospital during 2015-2019. All patients with confirmed diagnosis of Fournier gangrene were included in the study. Patients with isolated scrotal abscess without necrotizing fasciitis of perineal or inguinal area were excluded. Data were collected from the medical record of the study period.

Variables collected in the study included age, sex, comorbidity, management, complications, and outcomes and FGSI scoring. Complications in this study were defined as any complications associated with Fournier gangrene; any preexisting medical condition of the patients was defined as comorbidity. FGSI scoring is calculated by the method previously outlined by Laor et al. and is composed of nine parameters: temperature, heart rate, respiratory rate, serum sodium level, potassium level, creatinine level, bicarbonate level, hematocrit, and leukocyte count. The nine parameters were scored with values of $0-4$. The scoring was performed at the time of presentation (either in emergency room or during outpatient visit).

Furthermore, the data were classified by the outcome of whether the patient was deceased or alive. Continuous data were presented as the mean with standard deviation, and were compared between groups by using the twosample $t$-test. Categorical data were presented by frequency and percentage, and were compared using the Chisquare test. Data analyses were performed by using SPSS version 17.0 software (SPSS Inc., Chicago, IL, USA).

\section{Results}

In this study, 83 patients were included from the period 2015-2019, and were divided into two groups; 60 patients were alive at the time this study was carried out (first group), and 23 of them were already deceased (second group). From the first group, the average age was $49.86 \pm 11.78$, and in the second group this was $55.86 \pm 13.56$, which was slightly older than the first group $(p=0.059)$. From the Charlson Comorbidity Index, we found the first group was $2.5(0-9)$, and the second group was $2(1-8)$, with diabetes being the most common comorbidity in both groups, with 24 patients (40\%) and 10 patients (43.5\%). Abscess formation followed in second place with 16 patients (26.7\%) and 7 patients $(30.4 \%)$, respectively $(\mathrm{p}=0.005)$. Hypertension $(9.4 \%)$, HIV (5.2\%), the presence of fistula $(6 \%)$, stricture $(6 \%)$, and malignancy (2.3\%) were also detected in patients' comorbid history. From the Fournier's Gangrene Severity Index (FGSI), in the first group we found the average score was $5.5(2-15)$, and the average was $14(10-19)$ in the second group, which is significantly higher than the first group $(p=$ 0.001). In our study with FGSI cut-off score, we found that in the first group, 42 patients $(70 \%)$ were alive and 1 died (4.3\%) with cut-off score $<9$, while 49 patients $(81.6 \%)$ were alive and 4 died (17.3\%) with cut off score $<11$. While in cut-off score $\geq 9,18$ patients $(30 \%)$ were alive, and 22 patients (95.7\%) had died, and 11 patients (18.3\%) were alive and 19 patients (82.6\%) had died with cut-off score $\geq 11$ points (Table 1 ).

The sensitivity of this scoring system was $72.73 \%$ and $95.65 \%$ for the specificity if the cut-off score was $\geq 9$, the sensitivity of this scoring system was $78.79 \%$ and $82.61 \%$ for the specificity if the cut-off score was $\geq 11$ (Table 2 , Figure 1). 
Table I Profile of Fournier Gangrene Patients

\begin{tabular}{|c|c|c|c|}
\hline & Group I (Survivor) $n=60$ & Group 2 (Non-Survivor) $n=23$ & $P$ value \\
\hline Age & $49.86 \pm 11.78$ & $55.86 \pm 13.56$ & 0.059 \\
\hline \multicolumn{4}{|l|}{ Physiological } \\
\hline GCS & $15(14-15)$ & $15(14-15)$ & 0.764 \\
\hline MAP & $86.46 \pm 22.35$ & $75.79 \pm 31.66$ & 0.146 \\
\hline Temperature & $37.39 \pm 0.791$ & $37.5 \pm 0.634$ & 0.441 \\
\hline Respiratory rate & $21.63 \pm 2.945$ & $25.75 \pm 5.972$ & 0.000 \\
\hline$\%$ Body surface area & $5.88 \pm 2.472$ & $5.66 \pm 2.135$ & 0.596 \\
\hline Charlson Comorbidity Index & $2.5(0-9)$ & $2(I-8)$ & 0.005 \\
\hline \multicolumn{4}{|l|}{ Comorbidity } \\
\hline Diabetes & $24(40 \%)$ & $10(43.5 \%)$ & 0.482 \\
\hline Hypertension & $6(10 \%)$ & $2(8.7 \%)$ & 0.611 \\
\hline HIV & I (I.7\%) & $2(8.7 \%)$ & 0.184 \\
\hline Fistula & $2(3.3 \%)$ & $2(8.7 \%)$ & 0.306 \\
\hline Abscess & $16(26.7 \%)$ & 7 (30.4\%) & 0.465 \\
\hline Stricture & $\mathrm{I}(\mathrm{I} .7 \%)$ & I (4.3\%) & 0.480 \\
\hline Malignancy & $0(0 \%)$ & $3(4.5 \%)$ & 0.298 \\
\hline Heart disorder & I (4.3\%) & $2(3 \%)$ & 0.763 \\
\hline \multicolumn{4}{|l|}{ Laboratory data } \\
\hline $\mathrm{Hb}$ & $11.87 \pm 3.25$ & $10.57 \pm 3.00$ & 0.362 \\
\hline $\mathrm{Ht}$ & $33.84 \pm 8.76$ & $31.46 \pm 8.72$ & 0.272 \\
\hline Leucocyte & $17,297.63 \pm 8675.54$ & $28,596.57 \pm 45,6 \mid 2.76$ & 0.071 \\
\hline Thrombocyte & $382,847.46 \pm|67,59| .03$ & $263,043.48 \pm 147,134.9$ & 0.003 \\
\hline Sodium & $|30.8| \pm 5.8 \mid$ & $128.70 \pm 7.77$ & 0.248 \\
\hline Calcium & $4.55 \pm 4.49$ & $4.30 \pm 1.03$ & 0.694 \\
\hline Urea & $65.01 \pm 57.32$ & $105.22 \pm 65.45$ & 0.014 \\
\hline Creatinin & $2.12 \pm 2.66$ & $1.94 \pm 1.06$ & 0.658 \\
\hline $\mathrm{HCO}_{3}$ & $26.7 \pm 13.48$ & $23.68 \pm 12.27$ & 0.336 \\
\hline GDS & $176.87 \pm 130.77$ & $160.94 \pm 88.68$ & 0.566 \\
\hline Albumin & $2.90 \pm 1.76$ & $2.16 \pm 14.32$ & 0.165 \\
\hline Length of hospitalization & $25.5(I-7 I)$ & $5(2-3 \mid)$ & 0.000 \\
\hline FGSI & $5.5(2-15)$ & $14(10-19)$ & 0.000 \\
\hline$<9$ & $42(70 \%)$ & I (4.3\%) & 0.000 \\
\hline$\geq 9$ & $18(30 \%)$ & $22(95.7 \%)$ & \\
\hline$<11$ & 49 (81.6\%) & $4(17.3 \%)$ & \\
\hline$\geq 11$ & II (I8.3\%) & 19 (82.6\%) & \\
\hline$\geq 14$ & $9(15 \%)$ & $14(60.8 \%)$ & \\
\hline$<14$ & $51(85 \%)$ & $9(39.1 \%)$ & \\
\hline qSOFA score & $0(0-3)$ & I $(0-3)$ & 0.007 \\
\hline \multicolumn{4}{|l|}{ Other procedures } \\
\hline Colostomy & $3(13 \%)$ & 8 (12.1\%) & 0.908 \\
\hline Cystostomy & I (4.3\%) & $3(4.5 \%)$ & 0.969 \\
\hline
\end{tabular}

Note: Statistically significant $(p<0.05)$.

\section{Discussion}

In both men and women, Fournier's gangrene is a rapidly developing idiopathic infection of the external genitals and perineum. The gangrene results from a polymicrobial infection whose probable cause is endarteritis obliterans of the small and superficial veins. Mortality may occur at varying rates, starting from $4 \%$ to $88 \%$ of all males with the condition. It occurs at a higher frequency in males 
Table 2 Reliability of FGSI Based on Cut-Off Score

\begin{tabular}{|l|c|c|}
\hline & Cut Off Score $\geq 9$ & Cut Off Score $\geq$ I I \\
\hline Sensitivity & $72.73 \%$ & $78.79 \%$ \\
Specificity & 95.65 & $82.61 \%$ \\
Positive likelihood ratio & 18.25 & 4.65 \\
Negative likelihood ratio & 0.28 & 0.25 \\
PPV & 97.96 & $92.86 \%$ \\
NPV & $55 \%$ & $57.58 \%$ \\
\hline
\end{tabular}

compared with females. As such, a scoring system has been developed in order to aid with the prognostication of the patient.

Fournier Gangrene Severity Index (FGSI) was devised by Laor et al. in order to assess the risk of mortality in patients with Fournier gangrene (Table 3). Higher scores are associated with higher risk of mortality.

In our study, we found that mortality was higher in patients more than 50 years old. From the first group, the average age was $49.86 \pm 11.78$, and in the second group average age was $55.86 \pm 13.56$, which were slightly older than the first group $(p=0.059)$. This was consistent with findings in other studies.

Although the majority of the patients presented in this study had diabetes, with 24 patients $(40 \%)$ and 10 patients
$(43.5 \%)$ in both groups respectively, other predisposing factors including hypertension (9.4\%), HIV (5.2\%), the presence of fistula $(6 \%)$, stricture $(6 \%)$, and malignancy $(2.3 \%)$ were also detected. While there is still debate about whether having diabetes affects prognosis, our findings are consistent with observations that diabetes is associated with a higher mortality rate.

The FGSI is a good prognostic tool for assessing patients with Fournier gangrene. ${ }^{4}$ Mean FGSI in our study was $5.5(2-15)$ in the surviving patients (first group), and an average of 14 (10-19) in the deceased patients (second group), which is significantly higher than the first group $(\mathrm{p}=0.001)$. In our study, 11 points was agreed to be taken as the cut-off score rather than 9 as the other study does, but we have still taken the 9-points

\section{ROC Curve}
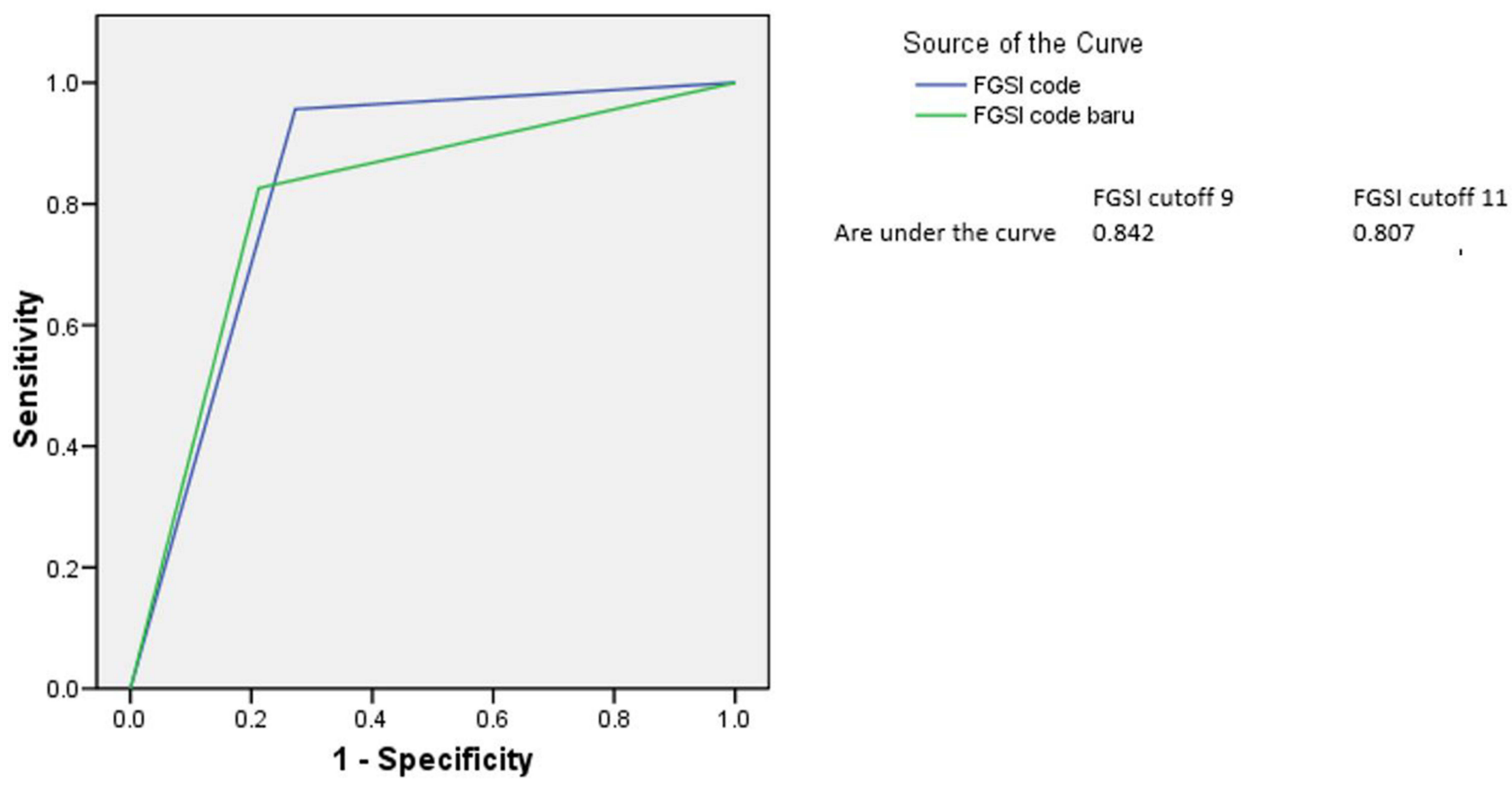

Figure I ROC curve for cut-off comparison. 
Table 3 FGSI Score ${ }^{10}$

\begin{tabular}{|c|c|c|c|c|c|c|c|c|c|}
\hline \multirow{2}{*}{$\begin{array}{l}\text { Variables } \\
\text { Numerical Score }\end{array}$} & \multicolumn{3}{|c|}{ High Abnormal Values } & \multicolumn{3}{|c|}{ Normal Values } & \multicolumn{3}{|c|}{ Low Abnormal Values } \\
\hline & $4+$ & $3+$ & $2+$ & $\mathrm{I}+$ & 0 & $1+$ & $2+$ & $3+$ & $4+$ \\
\hline Temperature ${ }^{\circ} \mathrm{C}$ & $>41$ & $39-40.9$ & - & $38.5-38.9$ & $36-38.4$ & $34-35.9$ & $32-33.9$ & $30-31.9$ & $<29.9$ \\
\hline Heart Rate & $>180$ & $140-179$ & $110-139$ & - & $70-109$ & - & $56-59$ & $40-54$ & $<39$ \\
\hline Respiratory Rate & $>50$ & $35-49$ & - & $25-34$ & $12-24$ & $10-11$ & $6-9$ & - & $<5$ \\
\hline Serum sodium (mmol/l) & $>180$ & $160-179$ & $155-159$ & $150-154$ & $130-149$ & - & $120-129$ & $111-119$ & $<110$ \\
\hline Serum potassium (mmol/l) & $>7$ & $6-6.9$ & - & $5.5-5.9$ & $3.5-4$ & $3-3.4$ & $2.5-2.9$ & - & $<2.5$ \\
\hline Serum creatinine $(\mathrm{mg} / 100 \mathrm{~mL})$ & $>3$ & $2-3.4$ & $1.5-1.9$ & - & $0.6-1.4$ & - & $<0.6$ & - & - \\
\hline Hematocrit (\%) & $>60$ & - & $50-59.9$ & $46-49$ & $30-45.9$ & - & $20-29.9$ & - & $<20$ \\
\hline Leukocytes (total/mm3 x 1000) & $>40$ & - & $20-39.9$ & $15-19.9$ & $3-14.9$ & - & - & $\mathrm{I}-2.9$ & - \\
\hline < I Serum bicarbonate $(\mathrm{mmol} / \mathrm{l})$ & $>52$ & $4|-5| .9$ & - & $32-40.9$ & $22-31.9$ & - & $18-21.9$ & $15-17.9$ & $<15$ \\
\hline
\end{tabular}

cut-off FGSI into account. Between these two cut-off scores ( 9 vs 11), we found that in the first group, 42 patients $(70 \%)$ were alive and 1 died $(4.3 \%)$ with cut off score $<9$, while 49 patients $(81.6 \%)$ were alive and 4 died $(17.3 \%)$ with cut off score $<11$. While in cut-off score $\geq 9$, 18 patients $(30 \%)$ were alive, and 22 patients $(95.7 \%)$ had died, and 11 patients $(18.3 \%)$ were alive and 19 patients $(82.6 \%)$ had died with cut-off score $\geq 11$ points. From these findings, we could see that the number of patients deceased in cut-off score $\geq 9$ points group were higher than in the $\geq 11$ points group by a sizeable margin, $95.7 \%$ and $82.6 \%$ respectively $(p=0.001)$. And the number of patients that survived in the second group was lower $(4.3 \%)$ in cut-off score $<9$ points, rather than in $<11$ points $(17.3 \%)$. This means that the cut-off score of 9 points still gives the most consistent result with the other study, which also stated the same thing, that 9 points sufficiently gives a sensitive and specific result, with sensitivity and specificity of $65-88 \%$ and $70-100 \%$, respectively.

This study was limited by its retrospective design, insufficiency of some data within the registry, and inability to access all data. Despite the limitations that we have, the large number of samples that we used makes our study more objective and reliable. Hence, this study has clinical importance to contribute meaningful perspectives for several stakeholders.

\section{Conclusion}

Fournier gangrene is a medical condition with relatively high mortality despite the aggressive and early treatment administered to the patient. Higher scores were associated with higher risk of mortality; mortality rates had exceeded
$75 \%$ with patients scoring more than 9 points in FGSI. The tool is sufficiently sensitive and specific with sensitivity and specificity of $72-78 \%$ and $82-95 \%$. FGSI is an effective modality to predict the disease and mortality risk of the patients, which is in line with previous research.

\section{Data Sharing Statement}

All data generated or analyzed during this study can be requested from the corresponding author.

\section{Ethics Approval and Consent to Participate}

The Ethical Committee of Hasan Sadikin General Hospital Bandung gave approval for this study. All patient admitted to Hasan Sadikin General Hospital should sign consent to disclose medical resume for educational and research purposes.

\section{Funding}

There is no funding to report.

\section{Disclosure}

The authors report no conflicts of interest in this work.

\section{References}

1. Mallikarjuna MN, Vijayakumar A, Patil VS, Shivswamy BS. Fournier's gangrene: current practices. ISRN Surg. 2012;2012:942437. doi:10.5402/2012/942437

2. Chernyadyev SA, Ufimtseva MA, Vishnevskaya IF, et al. Fournier's gangrene: literature review and clinical cases. Urol Int. 2018;101 (1):91-97. doi: $10.1159 / 000490108$

3. Thwaini A, Khan A, Malik A, et al. Fournier's gangrene and its emergency management. Postgrad Med J. 2006;82(970):516-519. doi:10.1136/pgmj.2005.042069 
4. Laor E, Palmer LS, Tolia BM, Reid RE, Winter HI. Outcome prediction in patients with Fournier's gangrene. J Urol. 1995;154 (1):89-92. doi:10.1016/S0022-5347(01)67236-7

5. Jiménez-Pacheco A, Arrabal-Polo MÁ, Arias-Santiago S, ArrabalMartín M, Nogueras-Ocaña M, Zuluaga-Gómez A. Fournier gangrene: description of 37 cases and analysis of associated health care costs. Actas Dermosifiliogr. 2012;103(1):29-35. doi:10.1016/j. ad.2011.04.007

6. Tuncel A, Aydin O, Tekdogan U, Nalcacioglu V, Capar Y, Atan A. Fournier's gangrene: three years of experience with 20 patients and validity of the Fournier's Gangrene Severity Index Score. Eur Urol. 2016;50(4):838-843. doi:10.1016/j.eururo.2006.01.030

7. Üreyen O, Acar A, Gökçelli U, Atahan MK, Ilhan E. Usefulness of FGSI and UFGSI scoring systems for predicting mortality in patients with Fournier's gangrene: a multicenter study. Ulus Travma Acil Cerrahi Derg. 2017;23(5):389-394.
8. Yilmazlar T, Ozturk E, Ozguc H, Ercan I, Vuruskan H, Oktay B. Fournier 's gangrene: an analysis of 80 patients and a novel scoring system. Tech Coloproctol. 2010;14:217-223. doi:10.1007/s10151010-0592-1

9. Egin S, Kamali S, Hot S, Gökçek B, Yesiltas M. Comparison of mortality in Fournier's gangrene with the two scoring systems. J Coll Physicians Surg Pakistan. 2020;30(1):67-72. doi:10.29271/ jcpsp.2020.01.67

10. Doluoğlu ÖG, Karagöz MA, Kılınç MF, et al. Overview of different scoring systems in Fournier's Gangrene and assessment of prognostic factors. Turk J Urol. 2016;42(3):190-196. doi:10.5152/ tud.2016.14194

\section{Publish your work in this journal}

Research and Reports in Urology is an international, peer-reviewed, open access journal publishing original research, reports, editorials, reviews and commentaries on all aspects of adult and pediatric urology in the clinic and laboratory including the following topics: Pathology, pathophysiology of urological disease; Investigation and treatment of urological disease; Pharmacology of drugs used for the treatment of urological disease. The manuscript management system is completely online and includes a very quick and fair peer-review system, which is all easy to use. Visit http://www.dovepress.com/ testimonials.php to read real quotes from published authors. 